\title{
A Griscelli syndrome type 2 murine model of hemophagocytic lymphohistiocytosis (HLH)
}

\author{
Jana Pachlopnik Schmid ${ }^{1,2,3}$, Chen-Hsuan $\mathrm{Ho}^{1,2}$, Julien Diana \\ Gérard Pivert ${ }^{5}$, Agnès Lehuen ${ }^{4}$, Frédéric Geissmann ${ }^{5,6}$, Alain Fischer ${ }^{1,2,3}$ \\ and Geneviève de Saint Basile
}

\footnotetext{
${ }^{1}$ Institut National de la Santé et de la Recherche Médicale U768, Laboratoire du Développement Normal et Pathologique du Système Immunitaire, Paris, France

${ }^{2}$ Faculté de Médecine de l'Université René Descartes, Institut Fédératif de Recherche Necker Enfants-Malades (IFR94), Université Paris Descartes, Paris, France

${ }^{3}$ Assistance Publique-Hôpitaux de Paris, Hôpital Necker Enfants-Malades, Unité d'Immunologie et Hématologie Pédiatrique, Paris, France

${ }^{4}$ Institut National de la Santé et de la Recherche Médicale U561, Hôpital Saint Vincent de Paul, Paris, France

${ }^{5}$ Assistance Publique-Hôpitaux de Paris, Hôpital Necker Enfants-Malades, Service d'Anatomie et de Cytologie Pathologiques, Paris, France

${ }^{6}$ Faculté de Médecine de l'Université René Descartes, Institut National de la Santé et de la Recherche Médicale U838, Hôpital Necker-Enfants Malades, Paris, France
}

Griscelli syndrome type 2 is caused by mutations in the RAB27A gene and is a rare and potentially fatal immune disorder associated with hemophagocytic lymphohistiocytosis (HLH). Animal models could provide assistance for better understanding the mechanisms and finding new treatments. Rab27a-deficient (ashen) mice do not spontaneously develop HLH. When injected with lymphocytic choriomeningitis virus (LCMV) strain WE, Rab27adeficient C57BL/6 mice developed wasting disease, hypothermia, splenomegaly, cytopenia (anemia, neutropenia and thrombocytopenia), hypertriglyceridemia and increased levels of IFN- $\gamma$, TNF- $\alpha$, GM-CSF, IL-12, CCL5 and IL-10. Activated macrophages with hemophagocytosis were found in liver sections of these mice. Compared with perforin-deficient mice, LCMV-infected Rab27a-deficient mice showed a substantially better survival rate and slightly higher viral doses were needed to trigger HLH in Rab27a-deficient mice. This study demonstrates that LCMV-infected Rab27a-deficient C57BL/6 mice develop features consistent with HLH and, therefore, represent a murine model of HLH in human Griscelli syndrome type 2 .

Key words: Animal models • Clinical immunology • Cytotoxicity • Immunodeficiencies

\section{Introduction}

Griscelli syndrome type 2 (OMIM no. 607624) is an autosomal recessively inherited, rare immune disorder associated with

Correspondence: Dr. Jana Pachlopnik Schmid

e-mail: jana.pachlopnik@inserm.fr hypopigmentation [1]. Mutations in the gene encoding the small GTPase Rab27a are responsible for Griscelli syndrome type 2 [2] and the corresponding mouse model, Rab27a ${ }^{\text {ash }}$ mice [3]. Rab27a-deficiency causes transport defects of cytotoxic granules, which lead to impaired cytotoxicity [4] and are associated with an uncontrolled, T-lymphocyte and macrophage activation syndrome and production of large quantities of cytokines, including IFN- $\gamma$, IL-6, IL-18, TWEAK and TNF- $\alpha$ [5-8]. Hypercytokinemia and cell 

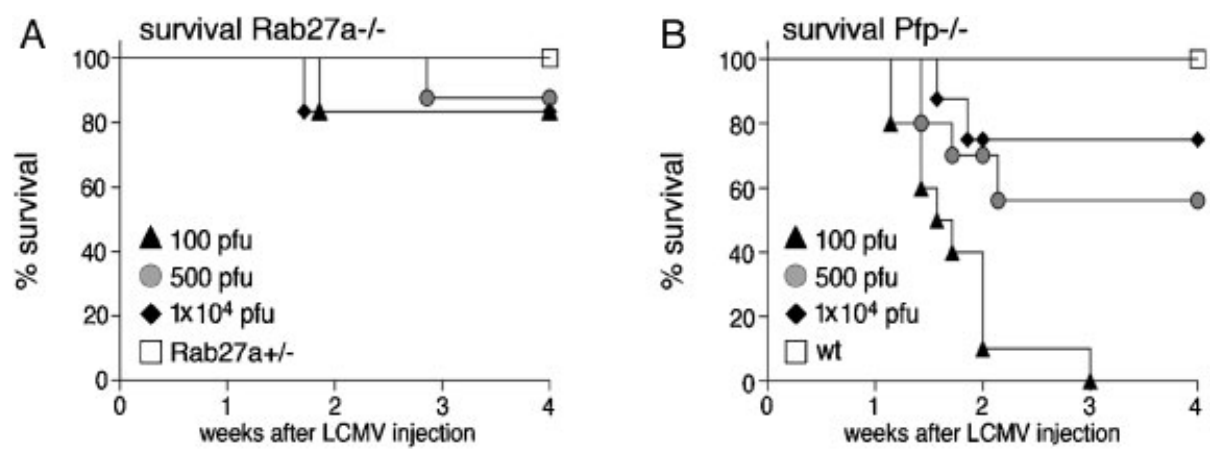

\begin{tabular}{|c|c|c|c|c|c|c|}
\hline \multirow[b]{2}{*}{ Strain } & \multirow{2}{*}{$\begin{array}{c}\text { LCMV } \\
\text { dose (pfu) }\end{array}$} & \multirow{2}{*}{$\begin{array}{l}\text { Number of } \\
\text { experiments }\end{array}$} & \multicolumn{2}{|c|}{ Number of mice } & \multicolumn{2}{|c|}{ Total number of mice } \\
\hline & & & infected & survived & infected & survived \\
\hline \multirow{3}{*}{ Rab27a-/- } & 100 & 2 & 6 & 5 & & \\
\hline & 500 & 2 & 8 & 7 & 20 & $17(85 \%)$ \\
\hline & $1 \times 10^{4}$ & 2 & 6 & 5 & & \\
\hline \multirow{3}{*}{$\mathrm{Pfp} \%$} & 100 & 3 & 10 & 0 & & \\
\hline & 500 & 3 & 9 & 4 & 27 & $10(37 \%)$ \\
\hline & $1 \times 10^{4}$ & 2 & 8 & 6 & & \\
\hline
\end{tabular}
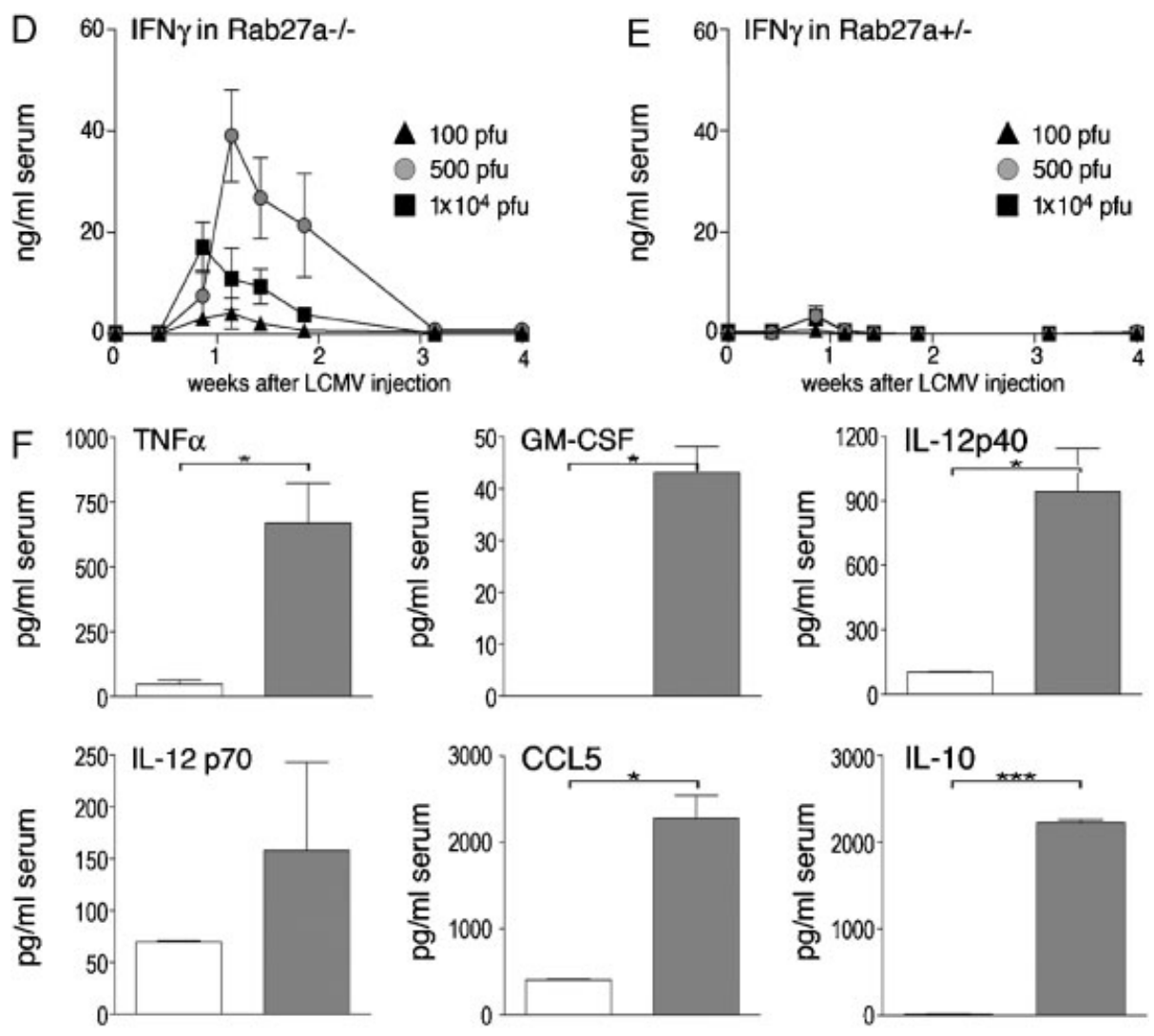

Figure 1. Susceptibility to LCMV and hypercytokinemia upon LCMV injection of Rab27a ${ }^{-/-}$mice. Survival of (A) Rab27a ${ }^{-/-}$and (B) pfp ${ }^{-1-}$ mice after injection of different doses of LCMV. Black triangles indicate mice injected with $100 \mathrm{PFU}$ LCMV; gray circles, $500 \mathrm{PFU}$; black diamonds, $1 \times 10^{4} \mathrm{PFU}$; and white squares Rab27 ${ }^{+/-}$(A) or wt (B) injected with 100,500 or $1 \times 10^{4} \mathrm{PFU}$, data are shown for $100 \mathrm{PFU}$ but the same result was obtained for 500 and $1 \times 10^{4} \mathrm{PFU}$. Data shown in (A) and (B) are pooled from two to three independent experiments as specified in (C), survival rate in Rab27a ${ }^{-1-}$ mice was higher than in $\mathrm{pfp}^{-/-}$mice after injection of the different LCMV doses $(p<0.05)$. Serum levels of IFN- $\gamma$ in (D) Rab27a $a^{-/-}$and (E) Rab27a ${ }^{+/-}$ (control) mice, as determined by ELISA, at various times after injection of different doses of LCMV. Black triangles indicate mice injected with 100 PFU LCMV; gray circles, 500 PFU; and black squares, $1 \times 10^{4} \mathrm{PFU}$. Mean \pm SD of duplicate measurements of six mice per group are shown. Serum levels of (F) TNF- $\alpha$, GM-CSF, IL-12 p40, IL-12 p70, CCL5 and IL-10 in Rab27a ${ }^{-1-}$ (gray bars) and Rab27a ${ }^{+/-}$mice (white bars) 13 days after injection of 500 PFU LCMV, as determined by Multiplex cytokine measurements. Data are representative for two independent experiments with at least four mice per group and are shown as mean $+\mathrm{SD}$. ${ }^{*} p<0.05,{ }^{* * *} p<0.001$. 
A

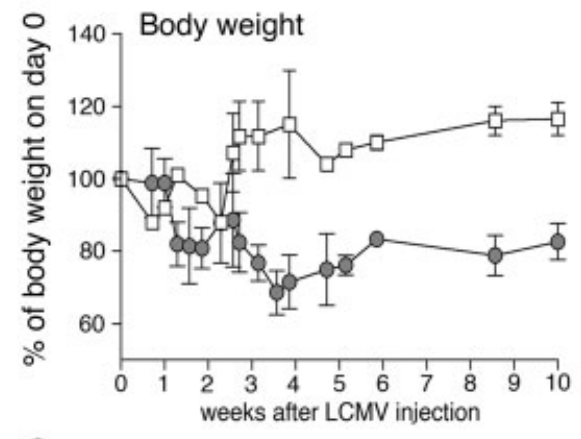

C

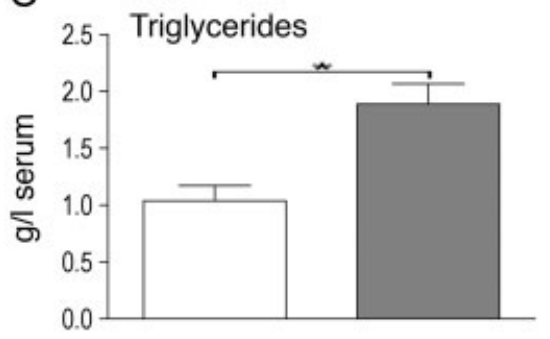

E

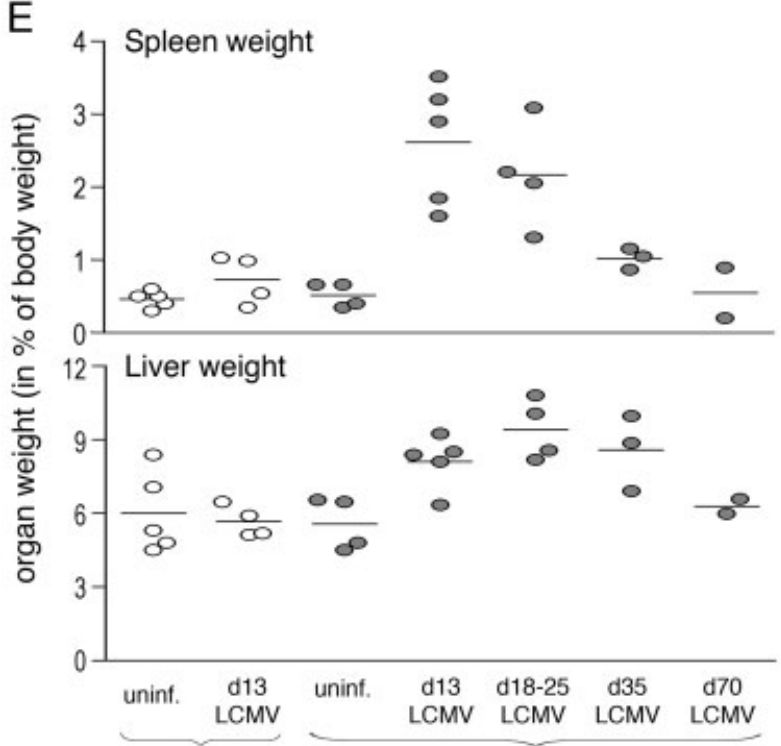

Rab27a+/-

Rab27a-/-
B

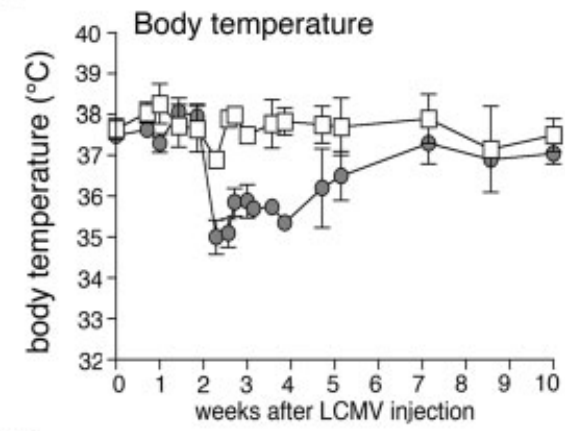

D

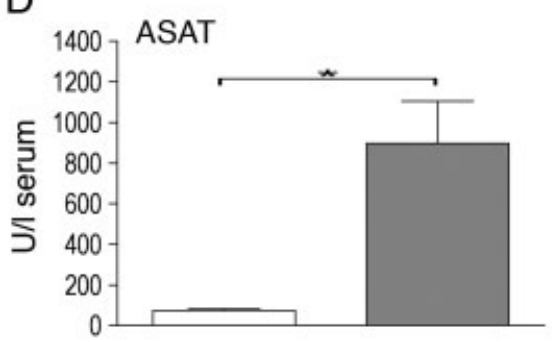

$\mathrm{F}$
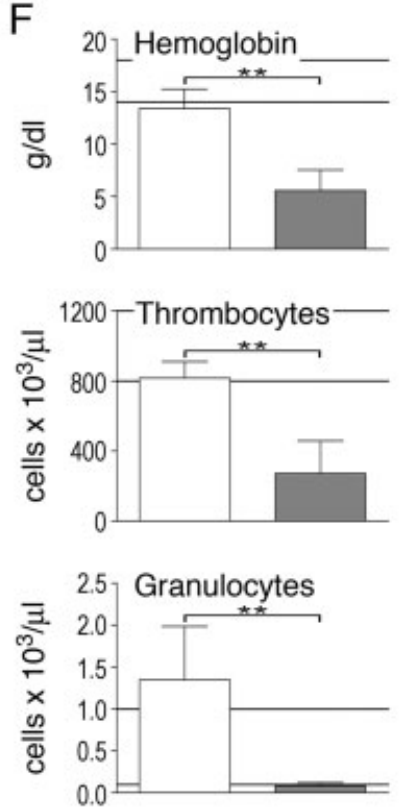

Figure 2. LCMV-infected Rab27 $\mathrm{a}^{-1-}$ mice display clinical and laboratory features of HLH. (A) Body weight and (B) body temperature of Rab27a ${ }^{-1-}$ (gray circles) and Rab27a ${ }^{+/}$(white squares) mice after injection of 500 PFU LCMV. Serum levels of (C) triglycerides and (D) aspartate aminotransferase (ASAT) in Rab27a $a^{-/-}$(gray bars) and Rab27a ${ }^{+/-}$(white bars) mice 13 days after injection of 500 PFU LCMV. Mean+SD of measurements in at least four mice per group are shown. (E) Spleen (upper panel) and liver (lower panel) weights in mice after injection of 500 PFU LCMV. White circles represent measurements in Rab27a ${ }^{+/-}$(control) mice, either uninfected or on day 13 after LCMV injection; gray circles $\mathrm{Rab}_{27 \mathrm{a}^{-1-}}$ either uninfected or on days 13, 18-25, 35 and 70 after LCMV injection. The horizontal lines represent mean of organ weights. (F) Blood hemoglobin level, thrombocyte and neutrophil granulocyte counts in Rab27a ${ }^{+/-}$(control) mice (white bars) and in Rab27a ${ }^{-1-}$ mice (gray bars) on day 13 after injection of 500 PFU LCMV. Mean+SD of measurements in five mice per group are shown. Lines correspond to normal values in C57BL/ $6 \mathrm{~J}$ wt mice given in the book by Metcalf [14]. ${ }^{*} p<0.05,{ }^{* *} p<0.005$.

infiltration of organs lead to the clinical and laboratory features of hemophagocytic lymphohistiocytosis (HLH) such as fever, splenomegaly, cytopenia, hyperferritinemia, hypofibrinogenemia and hypertriglyceridemia [9]. HLH in patients with Griscelli syndrome type 2 can be fatal and current treatment can have serious side effects. HLH can also be observed in patients who do not have any of these known, inherited defects; these acquired forms of HLH can occur in patients suffering from severe infections, malignancies and autoimmune, autoinflammatory or rheumatic diseases $[10,11]$ but may not have the very high fatality rate characteristic of the inherited forms of HLH. 
A
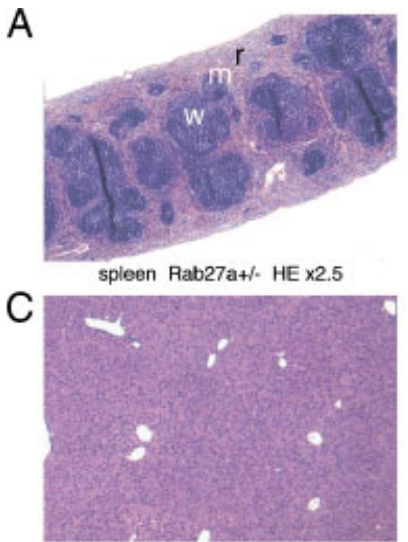

liver Rab27a+l- HE x10
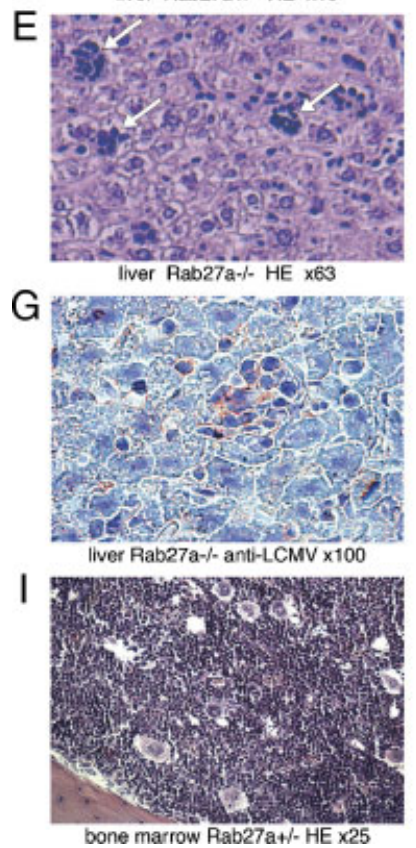

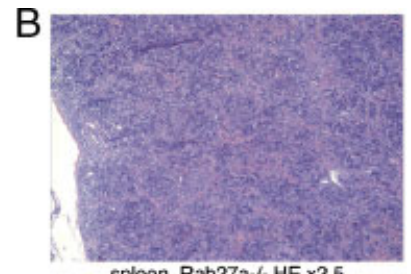

spleen Rab27a. $\%$ HE $\times 2.5$

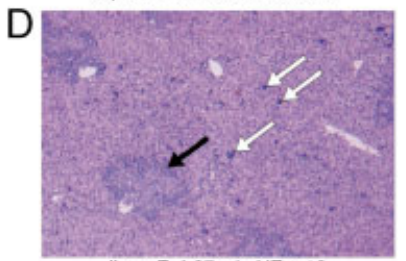

liver Rab27a $\%$ HE x10
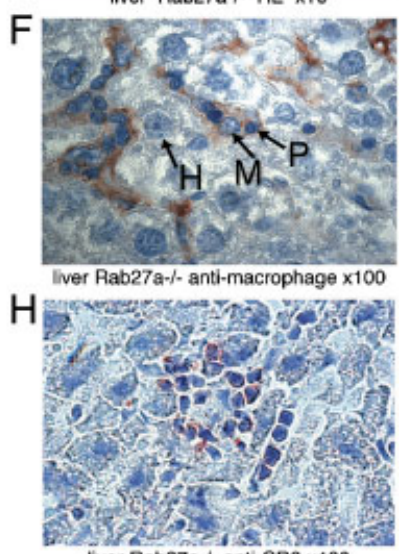

liver Rab27a $\%$ anti-CD $3 \times 100$

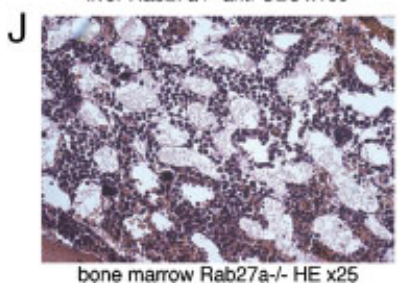

Figure 3. LCMV-infected Rab27 $\mathrm{a}^{-1-}$ mice display histologic features of HLH. Rab27a ${ }^{+/-}$and Rab27a ${ }^{-1-}$ mice were infected with 500 PFU LCMV and 13 days later the indicated tissues were isolated and stained. Spleen sections stained with H\&E of (A) a Rab27a ${ }^{+/-}$(control) mouse with preserved anatomical architecture $(\mathrm{r}=$ red pulp, $\mathrm{m}=$ marginal zone and $\mathrm{w}=$ white pulp) and (B) a Rab27a ${ }^{-1-}$ mouse with disorganized anatomical architecture and substantially enlarged spleen (original magnification $\times 2.5$ for both panels). Liver sections, H\&E stained, of (C) a Rab27a ${ }^{+/-}$(control) mouse and of (D) a Rab27a ${ }^{-1-}$ mouse with periportal infiltrates (black arrow) and intraparenchymal infiltrates (white arrows) (original magnification $\times 10$ ). (E) Detail of $(D)$, white arrows indicate intraparenchymal lymphocytic infiltrates (original magnification $\times 63$ ). Liver sections of a Rab27a ${ }^{-1-}$ mouse stained (in red) with ( $\mathrm{F}$ ) an anti-macrophage antibody (arrows indicate: $\mathrm{H}=$ nucleus of hepatocyte, $\mathrm{M}=$ nucleus of macrophage, $\mathrm{P}=$ phagocytosed cell, the combination of $\mathrm{M}$ and $\mathrm{P}$ indicating hemophagocytosis), (G) anti-LCMV and (H) anti-CD3 antibodies (original magnification $\times 100$ ). Bone marrow sections, H\&E stained, of (I) a Rab27a ${ }^{+/-}$(control) mouse and (J) a Rab27a ${ }^{-1-}$ mouse (original magnification $\times 25$ ). Light microscopy was performed using Axioplan 2 microscope (Zeiss), a QICAM Fast 1394 camera and Qcapture software (Qimaging). Image processing (i.e. uniform adjustment of brightness of all images without altering any features, and addition of labels) was done with Adobe Photoshop CS.

Animal models could provide assistance for better understanding the mechanisms of HLH and finding new treatments. Although it is known that C57BL/6J-Rab27a $\mathrm{a}^{\text {ash }} / \mathrm{J}\left(\mathrm{Rab}_{27 \mathrm{a}^{-/-}}\right.$) mice have an impaired cytotoxicity, it has not been described so far whether they develop HLH $[12,13]$. Infections can trigger HLH. The present study was conducted to investigate whether lymphocytic choriomeningitis virus (LCMV)-infected Rab27a ${ }^{-/-}$ mice would develop HLH and could therefore be considered a murine model of HLH in Griscelli syndrome.

\section{Results and discussion}

\section{LCMV-infected Rab27a ${ }^{-/-}$mice display clinical and laboratory features of HLH}

We investigated whether LCMV strain WE (LCMV WE)-infected $\mathrm{Rab}_{27} \mathrm{a}^{-/-}$mice would display the clinical and laboratory features required for the diagnosis of human HLH such as fever, splenomegaly, cytopenias and hemophagocytosis. After LCMV injection, $\mathrm{Rab} 7 \mathrm{a}^{-/-}$mice showed worsening of the general condition and one out of six mice receiving 100 or $1 \times 10^{4} \mathrm{PFU}$ and one out of eight receiving $500 \mathrm{PFU}$ died; as a control, perforin $^{-/-}$mice were infected with the same viral doses and ten out of ten mice receiving $100 \mathrm{PFU}$ LCMV, five out of nine receiving $500 \mathrm{PFU}$ and two out of eight receiving $1 \times 10^{4} \mathrm{PFU}$ died (Fig. 1A-C). IFN- $\gamma$ serum levels were increased in Rab27a ${ }^{-/-}$ mice, 6-13 days after LCMV injection and decreased below detection limit on day 22 while $\mathrm{Rab}_{27 \mathrm{a}^{+/-}}$(control) mice showed a moderate peak on day 6 (Fig. 1D and E). IFN- $\gamma$ levels were higher in those Rab27a $\mathrm{a}^{-/-}$mice that had been injected with 500 PFU LCMV than in those receiving a higher $\left(1 \times 10^{4} \mathrm{PFU}\right)$ or a lower dose (100 PFU). We considered that $500 \mathrm{PFU}$ represented a viral dose that was high enough to efficiently elicit an immune reaction as based on IFN- $\gamma$ serum level and, therefore, this viral dose was used for further experiments. Increased serum levels of macrophage-dependent cytokines TNF- $\alpha$, GM-CSF, IL-12 and predominantly T-cell-dependent cytokines (additionally to IFN- $\gamma$ ) such as CCL5 and IL-10 were detected in Rab27a $a^{-/-}$mice when compared with heterozygous littermates 13 days after injection of 500 (as in L36.) PFU LCMV (Fig. 1F). These values normalized with time (data not shown). Clinically, Rab27a ${ }^{-/-}$were visibly more ill than control mice, as assessed by observation of scrubby fur from day 7 post-LCMV injection on, lethargy (reduced mobility, reduced defense reactions) and loss of color in the padding of the front and rear paws on about days 8-20. Weight loss was observed in both, Rab27a $\mathrm{a}^{-/-}$and control mice, in the second week after LCMV injection. Within the third week, control mice regained weight whereas Rab27a ${ }^{-/-}$mice were still loosing weight (Fig. 2A). Rab27a $\mathrm{a}^{-/-}$mice started to regain body weight about 5 wk after LCMV injection but did not catch up with the weight of the littermates. Control mice were febrile 6-8 days after LCMV injection and had normal to slightly elevated body temperature thereafter. In contrast, $\mathrm{Rab}_{2} 7 \mathrm{a}^{-/-}$mice became febrile about 2 days later and were hypothermic thereafter. Their 
body temperature normalized $7 \mathrm{wk}$ after LCMV injection (Fig. 2B). Increased serum levels of triglycerides and liver transaminases were also found in Rab27a $\mathrm{a}^{-/-}$mice 13 days after LCMV injection when compared with heterozygous littermates (Fig. 2C and D). Splenomegaly, a slightly increased liver size and lymphadenopathies were observed in mice that were analyzed 13, 18, 21 and 25 days after LCMV injection (Fig. 2E and data not shown) while the organ sizes tended to return to normal afterwards (days 35 and 70). Severe pancytopenia was observed in Rab27a ${ }^{-/-}$mice 13 days after LCMV injection whereas control mice had hemoglobin levels and thrombocyte counts at the lower limit of the normal range and neutrophilia (Fig. 2F).

\section{LCMV-infected Rab27 $\mathrm{a}^{-/-}$mice display histopathologic features of HLH}

Histopathological changes consistent with HLH were present in Rab27a $\mathrm{a}^{-/-}$mice 13 days after LCMV injection whereas they were absent in $\mathrm{Rab}_{27} \mathrm{a}^{+/-}$mice infected with the same viral dose and sacrificed also on day 13 . While the splenic architecture was preserved in LCMV-infected Rab27a ${ }^{+/-}$control mice, since red pulp, marginal zone and white pulp were identifiable, the anatomical structure was completely disorganized with lost distinction between red and white pulp in $\mathrm{Rab}_{27} \mathrm{a}^{-1-}$ mice (Fig. 3A and B). The main histopathological changes in the liver of $\mathrm{Rab}_{27 \mathrm{a}^{-/-}}$mice 13 days after LCMV injection were periportal lymphocytic infiltrates and intraparenchymal lymphocytic infiltrates (Fig. 3C-E). The latter consisted not only of lymphocytes but also of macrophages that had engulfed lymphocytes (i.e. hemophagocytosis) as revealed by immunohistochemistry (Fig. 3F). Additionally, these clusters contained cells that were positively stained for LCMV-antigen that were surrounded by $\mathrm{T}$ cells (Fig. 3G and $\mathrm{H}$ ). These pathological changes in the liver were absent in $\mathrm{Rab}_{27} \mathrm{a}^{+/-}$control mice 13 days after injection of the same LCMV dose. Bone marrow sections showed hypoplasia in $\mathrm{Rab}_{2} 7 \mathrm{a}^{-/-}$mice, while bone marrow cellularity was preserved in $\mathrm{Rab}_{27} \mathrm{a}^{+/-}$control mice 13 days after LCMV injection (Fig. 3I and J).

In summary, LCMV-infected Rab27 $\mathrm{a}^{-/-}$mice developed a severe wasting disease, change in body temperature, splenomegaly, hypertriglyceridemia and pancytopenia. Hemophagocytosis (macrophages that had engulfed other blood cells, namely lymphocytes) was found in liver sections. These features correspond to the diagnostic criteria of human HLH. Additionally, also relevant to human HLH in Griscelli syndrome, mice showed hypercytokinemia. In contrast to humans, who suffer from fever and develop hypothermia mostly only permortem, mice had hypothermia even if recovering later on. However, the pathophysiological importance of this difference is difficult to interpret. While this is the first report of HLH in LCMV WE-infected Rab27a ${ }^{-/-}$mice, other investigators have described some features of HLH in perforin-, Unc13-d- (the mouse orthologue to human Munc13-4) and SAP-deficient mice infected with the LCMV strains WE and Armstrong [15-17]. Similar

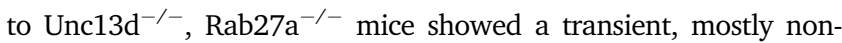
lethal course of the disease. In contrast to Unc13d $\mathrm{d}^{-/-}$mice that developed neutrophilia on day 12 after LCMV Armstrong-infection, which does not correspond to the diagnostic criteria in human HLH, LCMV WE-infected Rab27a ${ }^{-/-}$mice were neutropenic at this time and went through a transient neutrophilia $3 \mathrm{wk}$ later (not shown). Compared with perforin ${ }^{-/-}$, Rab27a $\mathrm{a}^{-/-}$mice showed better survival rates. This may correspond to the situation in humans, since HLH onset occurs later in patients with Rab27a-deficiency than in those with perforin-deficiency. This may be related to a residual cytotoxic function of Rab27a-deficient lymphocytes as suggested by studies showing in some conditions, a residual cytotoxic function of Rab27a-deficient $\mathrm{T}$ and NK cells [2, 18, 19]. A residual cytotoxic activity may be sufficient to deal with some but not all (especially persistent) infectious agents.

\section{Concluding remarks}

In conclusion, LCMV-infected $\mathrm{Rab}_{27} \mathrm{a}^{-/-}$mice developed features that correspond to the diagnostic criteria of human HLH. Thus, the present study describes a murine model of HLH in Griscelli syndrome. HLH in humans is a potentially fatal disease and current treatment can have serious side effects. Because of survival of HLH, LCMV-infected Rab27 $\mathrm{a}^{-/-}$mice represent a useful model to study the pathophysiology of HLH in more detail, including the role of dendritic cells, macrophages, NK and T cells. Additionally, this model could be useful for preclinical studies of differences between treatment and placebo groups of future treatments for inherited and acquired human HLH.

\section{Materials and methods}

\section{Mice}

C57BL/6J-wt, C57BL/6J-Prf1 $1^{\mathrm{tm} 1 \mathrm{Sdz}} / \mathrm{J}\left(\mathrm{pfp}^{-/-}\right)$and C3H/HeSnRab27a $\mathrm{a}^{\text {ash }} / \mathrm{J}$ mice were purchased from The Jackson Laboratory. C57BL/6J-Rab27a $\mathrm{a}^{\text {ash } / \mathrm{J}}\left(\mathrm{Rab}_{27 \mathrm{a}^{-/-}}\right)$were obtained by backcrossing $\mathrm{C} 3 \mathrm{H} / \mathrm{HeSn}-\mathrm{Rab} 27 \mathrm{a}^{\text {ash }} / \mathrm{J}$ with $\mathrm{C} 57 \mathrm{BL} / 6 \mathrm{~J}-\mathrm{wt}$ mice for ten generations. All mice were housed under specific pathogen-free conditions. Mice were maintained and handled in accordance with all relevant national and institutional polices. Body temperature was measured using a rodent rectal thermometer (BIOSEB).

\section{Virus}

LCMV WE [20], kindly provided by Professor Maries van den Broek and Professor Rolf Zinkernagel (University of Zürich, Switzerland), was injected intraperitoneally to 6-8 $\mathrm{wk}^{-o l d ~} \mathrm{pfp}^{-/-}$ and 6-14 wk-old Rab27a ${ }^{-/-}$mice. 


\section{Blood counts and cytokines}

Blood counts were determined using the MS 9-5 V automated cell counter (Melet Schloesing Laboratories). IFN- $\gamma$ levels were determined using an ELISA kit (R\&D Systems), the other cytokines by Bio-Plex custom-mixed immunoassays (BioRad Laboratories) run on a Bioplex 200 System.

\section{Immunohistochemistry}

Immunohistochemistry was performed using AEC Cell and Tissue Staining Kits (R\&D Systems) on formaline-fixed, araffineembedded sections with monoclonal rat $\operatorname{IgG}_{2 \mathrm{~b}}$ anti-mouse macrophage $\mathrm{F} 4 / 80$ antigen or on $4 \%$ paraformaldehyde-fixed cryosections incubated with monoclonal rat $\mathrm{IgG}_{1}$ anti-CD3 (Serotec AbD) or biotinylated $\mathrm{KL}-25$ mouse monoclonal $\mathrm{IgG}_{1}$ anti-LCMV WE GP-1 at $4^{\circ} \mathrm{C}$ overnight. Counterstaining was performed with hematoxylin. The KL-25 hybridoma was kindly provided by Professor Michael Buchmeier (Scripps Research Institute, USA) in agreement with Professor Demetrius Moskophidis (Medical College of Georgia, USA) [21].

\section{Statistical analysis}

Statistical hypothesis testing was performed with Prism version 4 for Macintosh (Graphpad) using two-tailed T-tests. Survival curves were compared using the log-rank test.

Acknowledgements: The authors thank Professor Olivier Bernard, Professor Francis Jaubert, Professor Bernard Lacour, Virginie Grondin, Dr. Juliette Lefebvre, Michèle Malassis-Séris, Nathalie Prince, Catherine Schaffner, Dr. Darin K. Fogg, Yoan Moreau, Nicolas Stadler and Dr. Joey Ting for their assistance. This work was supported by grants from the Institut National de la Santé et de la Recherche Médicale (INSERM), the Agence Nationale de la Recherche (ANR-05-MIM-010 and BLAN063_145379), the Fondation pour la Recherche Médicale (Equipe labélisée FRM 2007) and through Coordination Theme 1 of the European Community's FP7, Grant agreement number HEALTHF2-2008-201461. J. P. S. received grants from the Swiss Foundation for Grants in Medicine and Biology (SSMBS, Swiss National Science Foundation) no. 1211/PASMA-110658/1 and from the Fondazione Ettore e Valeria Rossi.

Conflict of interest: The authors have no financial or commercial conflicts of interest to declare.

\section{References}

1 Griscelli, C., Durandy, A., Guy-Grand, D., Daguillard, F., Herzog, C. and Prunieras, M., A syndrome associating partial albinism and immunodeficiency. Am. J. Med. 1978. 65: 691-702.
2 Menasche, G., Pastural, E., Feldmann, J., Certain, S., Ersoy, F., Dupuis, S., Wulffraat, N. et al., Mutations in RAB27A cause Griscelli syndrome associated with haemophagocytic syndrome. Nat. Genet. 2000. 25: 173-176.

3 Wilson, S. M., Yip, R., Swing, D. A., O’Sullivan, T. N., Zhang, Y., Novak, E. K., Swank, R. T. et al., A mutation in Rab27a causes the vesicle transport defects observed in Ashen mice. Proc. Natl. Acad. Sci. USA 2000. 97: 7933-7938.

4 Menasche, G., Feldmann, J., Fischer, A. and de Saint Basile, G., Primary hemophagocytic syndromes point to a direct link between lymphocyte cytotoxicity and homeostasis. Immunol. Rev. 2005. 203: 165-179.

5 Henter, J. I., Elinder, G., Söder, O., Hansson, M., Andersson, B. and Andersson, U., Hypercytokinemia in familial hemophagocytic lymphohistiocytosis. Blood 1991. 78: 2918-2922.

6 Osugi, Y., Hara, J., Tagawa, S., Takai, K., Hosoi, G., Matsuda, Y., Ohta, H. et al., Cytokine production regulating Th1 and Th2 cytokines in hemophagocytic lymphohistiocytosis. Blood 1997. 89: 4100-4103.

7 Takada, H., Takahata, Y., Nomura, A., Ohga, S., Mizuno, Y. and Hara, T., Increased serum levels of interferon-gamma-inducible protein 10 and monokine induced by gamma interferon in patients with haemophagocytic lymphohistiocytosis. Clin. Exp. Immunol. 2003. 133: 448-453.

8 Mazodier, K., Marin, V., Novick, D., Farnarier, C., Robitail, S., Schleinitz, N., Veit, V. et al., Severe imbalance of IL-18/IL-18BP in patients with secondary hemophagocytic syndrome. Blood 2005. 106: 3483-3489.

9 Henter, J. I., Horne, A., Aricó, M., Egeler, R. M., Filipovich, A. H., Imashuku, S., Ladisch, S. et al., HLH-2004: diagnostic and therapeutic guidelines for hemophagocytic lymphohistiocytosis. Pediatr. Blood Cancer 2007. 48: 124-131.

$10 \mathrm{Hsieh}, \mathrm{S}$. M. and Chang, S. C., Insufficient perforin expression in CD8+ $\mathrm{T}$ cells in response to hemagglutinin from avian influenza (H5N1) virus. J. Immunol. 2006. 176: 4530-4533.

11 Emmenegger, U., Schaer, D. J., Larroche, C. and Neftel, K. A., Haemophagocytic syndromes in adults: current concepts and challenges ahead. Swiss Med. Wkly. 2005. 135: 299-314.

12 Stinchcombe, J. C., Barral, D. C., Mules, E. H., Booth, S., Hume, A. N., Machesky, L. M., Seabra, M. C. and Griffiths, G. M., Rab27a is required for regulated secretion in cytotoxic T lymphocytes. J. Cell Biol. 2001. 152: 825-834.

13 Haddad, E. K., Wu, X., Hammer, J. A., 3rd and Henkart, P. A., Defective granule exocytosis in Rab27a-deficient lymphocytes from Ashen mice. J. Cell Biol. 2001. 152: 835-842.

14 Metcalf, D., Blood Lines, An Introduction to Characterizing Blood Diseases of the Post-genomic Mouse. Alpha Med Press, Durham, USA 2005.

15 Jordan, M. B., Hildeman, D., Kappler, J. and Marrack, P., An animal model of hemophagocytic lymphohistiocytosis (HLH): CD8+ T cells and interferon gamma are essential for the disorder. Blood 2004. 104: 735-743.

16 Crozat, K., Hoebe, K., Ugolini, S., Hong, N. A., Janssen, E., Rutschmann, S., Mudd, S. et al., Jinx, an MCMV susceptibility phenotype caused by disruption of Unc13d: a mouse model of type 3 familial hemophagocytic lymphohistiocytosis. J. Exp. Med. 2007. 204: 853-863.

17 Czar, M. J., Kersh, E. N., Mijares, L. A., Lanier, G., Lewis, J., Yap, G., Chen, A et al. Altered lymphocyte responses and cytokine production in mice deficient in the X-linked lymphoproliferative disease gene SH2D1A/ DSHP/SAP. Proc. Natl. Acad. Sci. USA 2001. 98: 7449-7454.

18 Plebani, A., Ciravegna, B., Ponte, M., Mingari, M. C. and Moretta, L., Interleukin-2 mediated restoration of natural killer cell function in a patient with Griscelli syndrome. Eur. J. Pediatr. 2000. 159: 713-714.

19 Gazit, R., Aker, M., Elboim, M., Achdout, H., Katz, G., Wolf, D. G., Katzav, S. and Mandelboim, O., NK cytotoxicity mediated by CD16 but not by NKp30 is functional in Griscelli syndrome. Blood 2007. 109: 4306-4312. 
20 Battegay, M., Cooper, S., Althage, A., Bänziger, J., Hengartner, H. and Zinkernagel, R. M., Quantification of lymphocytic choriomeningitis virus with an immunological focus assay in 24- or 96-well plates. J. Virol Methods 1991. 33: 191-198.

21 Bruns, M., Cihak, J., Müller, G. and Lehmann-Grube, F., Lymphocytic choriomeningitis virus. VI. Isolation of a glycoprotein mediating neutralization. Virology 1983. 130: 247-251.

Abbreviations: HLH: hemophagocytic lymphohistiocytosis - LCMV: lymphocytic choriomeningitis virus . LCMV WE: LCMV strain WE Pfp $^{-1-}:$ C57BL/6J-Prf1 ${ }^{\text {tm1Sdz } / J ~} \cdot$ Rab27a $^{-1-}:$ C57BL/6J-Rab27a ${ }^{\text {ash } / J ~}$
Full correspondence: Dr. Jana Pachlopnik Schmid, INSERM U768, Hôpital Necker Enfants-Malades, 149 rue de Sèvres, 75015 Paris, France Fax: +33-1-42-73-06-40

e-mail: jana.pachlopnik@inserm.fr

Received: 8/5/2008

Revised: 25/8/2008

Accepted: 27/8/2008 